\title{
Is relaxation exercise therapy effective in the management of patients with severe arterial hypertension?
}

Olga D. Lebedeva (1), Abduahat A. Achilov (2), Zilola F. Mavlyanova (3), Alexey V. Baranov (2), Shachnosa A. Achilova (2), Natalya P. Sanina (4), Anatotyi D. Fesyun (1), Andrey P. Rachin (1), Maxim Yu. Yakovlev (1), Kirill V. Terentev (4), Igor V. Reverchuck (5), Alie S. Velilyaeva (3), Maria Chiara Maccarone (6), Stefano Masiero $(6,7)$

(1) Federal State Budgetary Institution "National medical research center for rehabilitation and balneology”, Ministry of Health of Russia, Moscow, Russia; (2) Federal State Budgetary Institution "Skobelkin State Scientific Center of Laser Medicine Federal Medical and Biological Agency of Russia”, Moscow, Russia; (3) Samarkand state medical institution, Samarkand, Uzbekistan; (4) State Budgetary Healthcare Institution M. Vladimirsky Moscow Regional Research Clinical Institute, Russia; (5) Federal State Autonomous Educational Institution of Higher Education FSAEI HE "Immanuel Kant Baltic Federal University"; (6) Physical Medicine and Rehabilitation School, University of Padova, Padua, Italy; (7) Rehabilitation Unit, Department of Neuroscience, University of Padova, Padua, Italy

This article is distributed under the terms of the Creative Commons Attribution Noncommercial License (CC BY-NC 4.0) which permits any noncommercial use, distribution, and reproduction in any medium, provided the original author(s) and source are credited.

\begin{abstract}
Arterial hypertension (AH) is a burning problem in the world. Antihypertensive pharmacological therapy combined by physical exercises is well-studied in patients with mild and moderate AH. However, studies that have investigated relaxation in patients with severe $\mathrm{AH}$ in addition to drug therapy are lacking. Optimization of a comprehensive treatment for patients with severe AH, by using a multicomponent rational antihypertensive pharmacotherapy (PT) with subsequent application of relaxation exercise therapy (RET). The study involved 32 male patients with severe AH. Initially, clinical-instrumental and laboratory examination, blood pressure registration and daily arterial blood pressure monitoring were carried out. Suitable PT was selected for all the patients. 3 months after starting PT the patients were divided in 2 groups. The patients of the 1st group were prescribed RET in addition to PT. The 2nd group of patients continued receiving PT alone. 3 months later, average daily blood pressure (ADBP)-syst and ADBP-diast were compared in both groups. Three months after PT both groups demonstrated a significant decrease in ADBP-syst and ADBP diast, but these indicators remained higher than normal and did not reach the target level. Three months after the inclusion of RET in the comprehensive treatment, the 1st group demonstrated a significant decrease in ADBP (systolic and diastolic), not only in comparison with the initial data, but also with the data observed three months after PT. After 6 months, ADBP-syst and ADBP-diast in the 1st group were significantly lower compared with those of patients in the 2nd group. The inclusion of RET in addition to a multicomponent antihypertensive PT is a promising treatment option for severe AH.
\end{abstract}

Key Words: Severe arterial hypertension; antihypertensive therapy; relaxation exercise therapy. Eur J Transl Myol 31 (4): 10327, 2021 doi: 10.4081/ejtm.2021.10327

Arterial hypertension (AH) is a burning problem in the world, including the Russian Federation. Medical scientists in Russia and abroad pay special attention to etiology, pathophysiology, pathogenesis, diagnosis, treatment and prognosis of $\mathrm{AH} .{ }^{1-17}$ The prevalence of $\mathrm{AH}$ among the adult population is from $30-45 \%$ up to $60 \%$ and it is more frequent among people over 60 years. ${ }^{18,19}$
Throughout the world, AH also significantly affects cardiovascular complications and results in high death rate. ${ }^{20}$ In recent years, scientists have made great progresses in the area of pharmacotherapy (PT) for patients with $\mathrm{AH}$. PT helps to achieve the target level of arterial blood pressure, particularly in patients with mild and moderate $\mathrm{AH}$. With a higher degree of $\mathrm{AH}$ (severe 
arterial hypertension - the $3^{\text {rd }}$ degree of arterial hypertension) the effectiveness of pharmacological therapy decreases and to achieve the target level of arterial blood pressure it is necessary to use a combination of all major groups of antihypertensive medicines. Despite the use of antihypertensive medications, in clinical practice it is not always possible to reduce the blood pressure of patients with severe AH. According to current classifications, severe arterial hypertension of the 3rd degree includes a persistent increase of systolic blood pressure $\geq 180$ and/or diastolic blood pressure $\geq 110 \mathrm{~mm}$ of mercury. For patients in this category the prospects of PT are significantly limited. Indeed, $\mathrm{AH}$ is known to be a systemic disease with functional and structural disorders occurring at the level of peripheral circulation with a subsequent limitation of the reserve blood flow, growth of peripheral vascular resistance and increase in severity of patients' condition. Medicines improve the peripheral circulation at rest to the normal range of values. However, the reserve blood flow does not fully restore. One of the main factors influencing the restoring of the reserve of systemic vascular resistance is the correct selection of a motor regime for patients. Physical and rehabilitation medicine specialists on cardiac rehabilitation teams ensure that behavioral lifestyle treatments and drug therapies are applied systematically and monitor patients' progress modifying the rehabilitative program and the motor regime. $^{21,22}$ Antihypertensive pharmacological therapy combined with physical exercises is well-studied in patients with mild and moderate $\mathrm{AH}$ of the $1^{\text {st }}$ and the $2^{\text {nd }}$ degrees, who preserve exercise tolerance. With strength training, the sympatho-adrenal system (SAS) and the renin-angiotensin system (RAS) are stimulated, the heart rate and the blood pressure increase. Vice-versa, with relaxing movements, the SAS and the RAS are suppressed, the heart rate is normalized, and the blood pressure is reduced; in addition blood supply is increased due to the inclusion and the restoration of reserve capillaries - angioneogenesis. ${ }^{23}$ Since patients with a severe degree of arterial hypertension have a significantly reduced exercise tolerance because of the

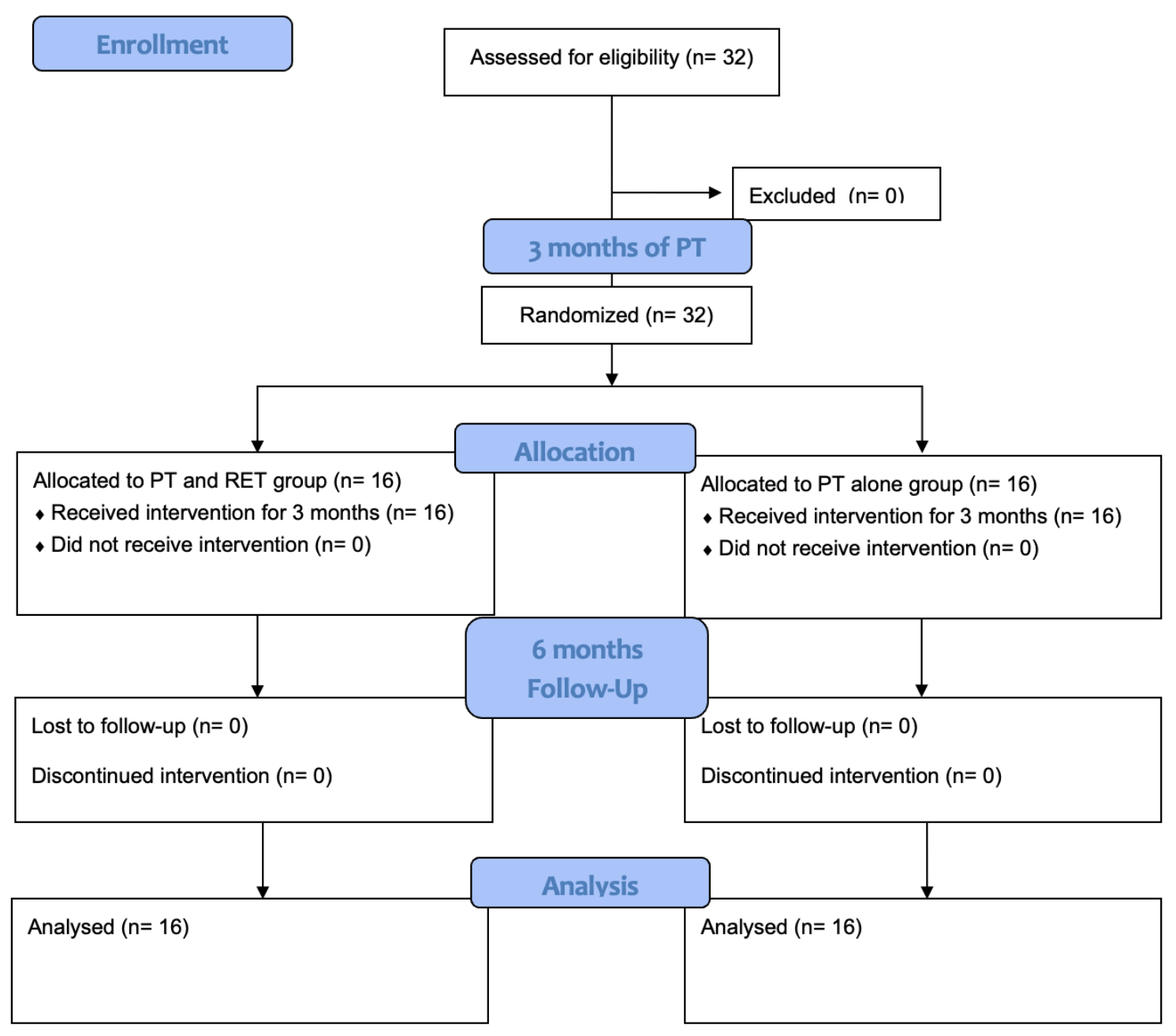

Fig 1. CONSORT 2010 Flow Diagram. Note: PT pharmacotherapy; RET relaxation exercise therapy. 
limited reserve of systemic vascular resistance, ${ }^{24}$ we hypothesize that relaxation exercise therapy (RET) can be a promising option for this type of patients. ${ }^{25}$ However, to our knowledge studies that have investigated relaxation in patients with severe $\mathrm{AH}$ in addition to drug therapy are lacking, so this study aims to investigate the efficacy and tolerability of a relaxation program performed in addition to standard PT. Indeed, aim of this study was optimization of a comprehensive treatment for patients with severe $\mathrm{AH}$, by using a multicomponent rational antihypertensive PT with subsequent application of RET.

\section{Materials and Methods}

\section{Participants}

The study involved 32 male patients with severe $\mathrm{AH}$, with their daily blood pressure being monitored, and average daily systolic blood pressure (ADBP-syst), average daily diastolic blood pressure (ADBP-diast), and heart rate (HR) being measured. Rational pharmacological therapy was selected for all the patients in accordance with clinical recommendations for the treatment of $\mathrm{AH}^{26,27}$ Rational PT consisted of a multicomponent antihypertensive therapy, including ACE inhibitors, beta-blockers, calcium antagonists, angiotensin II receptor blockers, diuretics, etc. The selection of the dose of multicomponent antihypertensive therapy was made based on the control of the clinical condition, blood pressure, heart rate and subjective perceptions of the patients.

\section{Intervention and procedure}

The patients received PT for 3 months. Then they were divided in 2 groups: the $1^{\text {st }}$ group (average age $46.3 \pm 6.8$ years) additionally to PT was prescribed RET; the $2^{\text {nd }}$ group (control group, average age $43.6 \pm 7.2$ years) continued to receive PT (Figure 1). All the participants signed informed consent. In addition to supportive PT, RET was individually selected for each patient from group 1 considering his individual characteristics. The selection of RET was carried out under the control of blood pressure, heart rate and clinical condition of the patient. A physical and rehabilitation medicine physician was included in the study and supervised the RET intervention. When performing RET, all the patients were engaged in exercise therapy on a daily basis for the entire observation period. All exercises were performed without strength tension. The norm group consisted of 16 practically healthy persons, average age $42.8 \pm 5.3$ years. After 6 months of comprehensive treatment and 3 months from randomization, a follow-up evaluation with reassessment of cardiovascular parameters was performed. The research procedures conformed to the Declaration of Helsinki.

\section{Statistical analysis}

The data were analyzed with SAS 9.4 program (SAS Institute Inc., NC, USA) and R-Studio for Windows. The level of statistical significance was set at $95 \%$ and the statistical tests used for analysis included Student's t-test for quantitative variables (differences obtained in different groups of patients and in the course of treatment).

\section{Results}

The results obtained after the comprehensive treatment demonstrated improvement of the subjective condition of the patients. Data presented in Table 1 indicated that at baseline the patients in both groups had significantly high ADBP-syst $(\mathrm{P}<0.001)$ and ADBP-diast $(\mathrm{P}<0.001)$.

The changes in the indicators suggested that in addition to a multicomponent antihypertensive pharmacological therapy, after 3 months: the $1^{\text {st }}$ and the $2^{\text {nd }}$ groups demonstrated a decrease in ADBP-syst, in the $1^{\text {st }}$ group $(\mathrm{P}<0.001)$ and in $2^{\text {nd }}$ group $(\mathrm{P}<0.001)$, respectively. An upward trend was observed in relation to ADBP-diast in the $1^{\text {st }}$ group $(\mathrm{P}<0.001)$, and in the $2^{\text {nd }}$ group $(\mathrm{P}<0.001)$, respectively (Table 2 ). Although, after 3 months of PT both groups demonstrated a significant decrease in ADBP, these indicators remained higher than normal and did not reach the target level. After 3 months of antihypertensive PT, RET was included in the comprehensive treatment course of the patients of the $1^{\text {st }}$ group. The patients in the $2^{\text {nd }}$ group continued receiving the multicomponent antihypertensive pharmacological therapy only. The results inTable 2 show that patients in the $1^{\text {st }}$ group demonstrated a significant decrease in ADBP-syst after 6 months of observations and 3 months after inclusion of RET, not only in comparison with the initial data $(\mathrm{P}<0.001)$, but also when compared with those that were after 3 months of $\mathrm{PT}$ alone $(\mathrm{P}<0.001)$. After 6 months, the indicators of ADBP-syst and ADBP-diast in

Table 1. Blood pressure (BP) and heart rate (HR) in patients with severe AH of the 1 st and the 2nd groups (M $\left.\pm_{M}\right)$

\begin{tabular}{|l|l|l|l|l|}
\hline Groups under study & $\begin{array}{l}\text { Healthy (norm) } \\
\mathrm{n}=16\end{array}$ & $\begin{array}{l}\text { Group 1 } \\
\mathrm{n}=16\end{array}$ & $\begin{array}{l}\text { Group 2 } \\
\mathrm{n}=16\end{array}$ & P Group 1 - Group 2 \\
\hline ADBP-syst mmHg & $122.0 \pm 1.4$ & $221.2 \pm 3.8^{* * *}$ & $218.4 \pm 4.1^{* * *}$ & Unrel \\
\hline ADBP-diast $\mathrm{mmHg}$ & $81.1 \pm 1.1$ & $117.8 \pm 2.8^{* * *}$ & $118.3 \pm 2.7^{* * *}$ & Unrel \\
\hline HR, per min & $68.4 \pm 2.1$ & $63.4 \pm 1.4$ & $65.3 \pm 1.6$ & Unrel \\
\hline
\end{tabular}

Note: $* * *_{-} P<0.001$ reliability of differences of the indicators in the $1^{\text {st }}$ and the $2^{\text {nd }}$ groups, compared with the norm; P Group 1- Group 2 - reliability of the differences between Group 1 and Group 2; Unrel - unreliable data. 
Table 2. Changes in blood pressure indicators in patients with severe arterial hypertension in the $1^{\text {st }}$ and the $2^{\text {nd }}$ groups after 2 and 6 months of treatment $\left(M \pm_{M}\right)$

\begin{tabular}{|c|c|c|c|}
\hline Indicators & $\begin{array}{l}\text { Group } 1 \\
\text { Baseline data }\end{array}$ & $\begin{array}{l}\text { Group 1, } \\
\text { after } 3 \text { months of PT }\end{array}$ & $\begin{array}{l}\text { Group } 1 \text {, } \\
\text { after } 3 \text { months of PT } \\
+3 \text { months of RET }+ \text { PT }\end{array}$ \\
\hline ADBP-syst mmHg & $221.2 \pm 3.8$ & $174.9 \pm 4.3^{* * *}$ & $152.8 \pm 3.8^{* * *} \mathrm{xx}$ \\
\hline ADBP-diast mmHg & $117.8 \pm 2.8$ & $97.4 \pm 2.7^{* * *}$ & $85.5 \pm 2.2^{* * *} \mathrm{xx}$ \\
\hline & $\begin{array}{l}\text { Group } 2 \\
\text { Baseline data }\end{array}$ & $\begin{array}{l}\text { Group 2, } \\
\text { after } 3 \text { months of PT }\end{array}$ & $\begin{array}{l}\text { Group 2, } \\
\text { after } 6 \text { months of PT }\end{array}$ \\
\hline ADBP-syst mmHg & $218.4 \pm 4.1$ & $171.7 \pm 4.0^{* * *}$ & $165.8 \pm 2.6^{* * *}$ \\
\hline ADBP-diast mmHg & $118.3 \pm 2.7$ & $93.9 \pm 2.1^{* * *}$ & $92.3 \pm 2.1^{* * *}$ \\
\hline $\begin{array}{l}\text { P- reliability of differences of } \\
\text { ADBP-syst in the } 1^{\text {st }} \text { group } \\
\text { compared with the } 2^{\text {nd }} \text { group } \\
\text { after } 3 \text { and } 6 \text { months of } \\
\text { treatment. }\end{array}$ & & Unrel & $<0.01$ \\
\hline $\begin{array}{l}\text { P- reliability of differences of } \\
\text { ADBP-diast in the 1st group } \\
\text { compared with the 2nd group } \\
\text { after } 3 \text { and } 6 \text { months of } \\
\text { treatment. }\end{array}$ & & Unrel & $<0.05$ \\
\hline
\end{tabular}

Note: PT pharmacotherapy; RET relaxation exercise therapy. $*_{-} P<0.05$; ** $P<0.01$; ***- $P<0.001$ - reliability of differences, compared with the baseline data; $x x-P<0.01$ - reliability of differences of the indicators after 3 and 6 months of treatment; Unrel - unreliable data.

the $2^{\text {nd }}$ group had a downward trend; compared with the observed results after 3 months, but the difference was unreliable. However, after 6 months ADBP-syst and ADBP-diast in the 1st group were significantly lower when compared with the same outcomes in the $2^{\text {nd }}$ group.

\section{Discussion}

This study showed the potential role of RET in AH management. Initially, both groups demonstrated a significant increase in ADBP-syst and ADBP-diast, compared with the normal level, without significant difference between the two group. Three months after PT both groups demonstrated a significant decrease in ADBP-syst and ADBP-diast, but these indicators remained higher than normal and did not reach the target level. Then, RET was included in the comprehensive treatment of the $1^{\text {st }}$ group. Three months after the inclusion of RET in the comprehensive treatment, the $1^{\text {st }}$ group demonstrated a significant decrease in ADBP (systolic and diastolic), not only in comparison with the initial data, but also with the data observed 3 months after PT. Moreover, after 6 months, ADBP-syst and ADBPdiast in the $1^{\text {st }}$ group were significantly lower when compared with the values of the $2^{\text {nd }}$ group, proving a significant clinical effectiveness of RET. The effects of exercise training in blood pressure levels and in its mechanisms of control are of clinical relevance and efficacy. Different exercise training modalities (aerobic, resistance, and concurrent training - combination of aerobic and resistance) contribute differently to blood pressure reduction and control. The blood pressure reduction seems not to be dependent on the type of exercise; aerobic, dynamic resistance, isometric resistance, and concurrent exercise seem equally effective in lowering baseline systolic blood pressure in comparison with control. ${ }^{28}$ Regular participation in aerobic exercise has been shown to result in a lowering of blood pressure in $\mathrm{AH}$ individuals. ${ }^{29,30}$. Higherintensity aerobic exercise, up to $70 \%$ of maximal oxygen consumption, seems not to produce a greater hypotensive effect, compared with moderate-intensity aerobic exercise. ${ }^{30}$ Dynamic resistance exercise seems to be as effective as aerobic exercise in reducing blood pressure among individuals with hypertension. ${ }^{31}$ Even though no doubt remains about the importance of physical exercise for the management of hypertension, the mechanisms of the beneficial effects have not been fully elucidated. Physical exercise, in the presence of $\mathrm{AH}$, seems effective in increasing the amplitude and decreasing the decay time of cytosolic calcium, suggesting a higher availability of intracellular calcium, faster removal of this ion from the cytosol, and consequently, increased cellular relaxation. MiRNA expression can also have a role in exercise effects on $\mathrm{AH}^{32}$ Relaxing environments (e.g., spa facilities) have been shown to contribute to the modulation of the immune system and inflammation. ${ }^{33-36}$ Inflammation cytokines have been demonstrated to play critical roles in endothelial and smooth muscle cell responses, contributing to endothelial dysfunction and 
the development of hypertension. ${ }^{37}$ In addition, mindbody practices that elicit the relaxation response (eight weekly individual training sessions including diaphragmatic breathing, body scan, mantra repetition, and mindfulness meditation) have been demonstrated to reduce blood pressure in essential hypertension. The response to relaxation interventions is characterized by a set of physiologic changes that include decreased oxygen consumption, decreased carbon dioxide elimination, decreased respiratory rate, increased low-frequency heart rate oscillations, and increased exhaled nitric oxide, in addition to specific changes in gene expression. Immune regulatory pathways genes have been shown to be downregulated after relaxation interventions, while glucose metabolism, cardiovascular system development, and circadian rhythm genes seemed to be upregulated. ${ }^{37}$ Only $20 \%$ of the capillary network of the human body is active at rest, while the remaining $80 \%$ of the capillaries are in a reserve state and they start working during physical activities, especially in the mode of relaxation movements. This means that the heart pump function services only $20 \%$ of the capillaries. It is known that the base of the cardiovascular system reserve is the capillary network. Therefore, for a complete recovery and preservation of the reserve of the cardiovascular system, along with supportive PT for patients with $\mathrm{AH}$, the inclusion of RET appears to be promising. ${ }^{24,}{ }^{25}$ Thus, it should be assumed that, since PT is not sufficient for the elimination of cellular-tissue and microcirculatory disorders in case of severe $\mathrm{AH}$, it should be advisable to include RET into the multicomponent treatment, and positive changes in the indicators of the $1^{\text {st }}$ group of patients after the inclusion of RET are suggestive of it.

\section{Limitations of the study}

Although these first results appear to be promising, further studies will define the number of sessions and the duration of treatment necessary to obtain a containment of blood pressure values. Another question to be investigated is the maintenance of RET after blood pressure reduction: it must be clarified if it is necessary to continue chronically the treatment for a better control of $\mathrm{AH}$. The small number of patients considered necessitates further evaluation extending the trial to a larger population. The present study is not registered on a clinical trial Registry. PT with the addition of RET will also need to be considered for different grades of $\mathrm{AH}$, stratifying the population according to the severity of disease. In addition, further studies may also evaluate functional tests in these patients. ${ }^{38}$ Finally, additional studies in the future should consider longer-term followup so as to assess the effects of combination therapy over time.

In conclusion, addition of RET into the background of a multicomponent antihypertensive PT is a promising option for severe AH. Further studies will better define the role of this intervention, even in the long term, for people with severe $\mathrm{AH}$.

\section{List of acronyms}

ADBP-diast -average daily diastolic blood pressure ADBP-syst - average daily systolic blood pressure

AH - Arterial hypertension

HR - heart rate

PT - pharmaco-therapy

RAS - renin-angiotensin system

RET - relaxation exercise therapy

SAS - sympatho-adrenal system

\section{Contributions of Authors}

A.A.A., K.V.T., Sh.A.A, I.V.R., collection and processing of the material, analysis of the obtained data; A.A.A., O.D.L., Sh.A.A, M.C.M., writing of the text; A.A.A., O.D.L., A.V.B., N. P. S., A.D.F., A.P.R., S.M., M.C.M., M.Yu.Y., M.Z.F., A.S.V., Scientific advising, editing

\section{Acknowledgments None.}

Funding None.

\section{Conflict of Interest}

The authors declare no possible conflicts of interest.

\section{Ethical Publication Statement}

We confirm that we have read the Journal's position on issues involved in ethical publication and affirm that this report is consistent with those guidelines.

\section{Corresponding Author}

Maria Chiara Maccarone, Physical Medicine and Rehabilitation School, University of Padova, Via Giustiniani 3, 35128 Padova, Italy.

ORCID -https://orcid.org/0000-0003-2793-1334

Email: mariachiara.maccarone@studenti.unipd.it

\section{E-mails and ORCID iD of co-authors}

Olga. D. Lebedeva: lebedeva-od@yandex.ru ORCID iD: 0000-0002-4435-2273

Abduahat A. Achilov: achilovaa@mail.ru ORCID iD: 0000-0001-7220-246X

Zilola F. Mavlyanova: reab.sammi@mail.ru ORCID iD: 0000-0001-7862-2625

Alexey V. Baranov: gnc lazmed@fmbamail.ru

ORCID iD: 0000-0002-7995-758X

Shachnosa A. Achilova: asa316@mail.ru

ORCID iD: 0000-0003-0024-9810

Natalia Petrovna Sanina: nataliasanina2@yandex.ru ORCID iD: 0000-0001-8597-1962

Anatoly D. Fesyun: fesyunad@nmicrk.ru

ORCID iD: 0000-0003-3097-8889

Andrey P. Rachin: rachinap@nmicrk.ru

ORCID iD: 0000-0003-4266-0050

Maxim Yu.Yakovlev: masdat@mail.ru

ORCID iD: 10000-0002-5260-8304

Kirill Vadimovich Terentev:

ORCID iD: 0000-0003-0858-1906
Kirillterentev184@gmail.com 
Igor V.Reverchuk: bios@reverchuk.com

ORCID iD: 0000-0002-3498-9094

Alie S.Velilyaeva: alsabvel@mail.ru

ORCID iD: 0000-0001-8986-1322

Stefano Masiero: stef.masiero@unipd.it

ORCID iD: 0000-0002-0361-4898

\section{References}

1. Xia N, Li H. The role of perivascular adipose tissue in obesity-induced vascular dysfunction. $\mathrm{Br} \mathrm{J}$ Pharmacol. 2017; 174 (20): 3425-3442. doi: 10.1111 / bph.13650.

2. Ramalingam L, Menikdiwela K, LeMieux M, Dufour JM, Kaur G, Kalupahana N, MoustaidMoussa N. The renin angiotensin system, oxidative stress and mitochondrial function in obesity and insulin resistance. Biochim Biophys Acta Mol Basis Dis. 2017 May;1863(5):1106-1114. doi: 10.1016/j.bbadis.2016.07.019. Epub 2016 Aug 4..

3. Aronov DM. History of cardiac rehabilitation in Russia. Kardiologiia. 2018;58(11S):14-21. doi: 10.18087/cardio.2604. (In Russ.).

4. Kontsevaya AV, Romanenko TS, Vygodin V, Fiitilev S.B. Pharmacoepidemiology and effectiveness of antihypertensive therapy in the specialized cardiological institution clinical practice. Rational pharmacotherapy in cardiology. 2015; 11(1):8-17. doi: 10.20996/1819-6446-201511-18-17.(In Russ.).

5. Aronov DM, Kozlova LV, Bubnova MG Current state and problems of cardiac rehabilitation in Russia. Cardiosomatics. 2017; 8 (3): 5-9. doi: 10.26442/2221-7185_8.3.5-9. (In Russ.).

6. Bubnova MG, Aronov DM. Cardiac rehabilitation: stages, principles and international classification of functioning (ICF). Preventive medicine. 2020;23(5):40-49. doi: 10.17116/profmed2020230 5140.

7. Chazova IE, Aksenova AV, Oshchepkova EV. Features of the course of arterial hypertension in men and women (according to the national register of arterial hypertension). Therapeutic archive. 2019. Vol 91 No. 1. pp. 4-12. doi: 10.26442/ 00403660.2019.01.000021.

8. Cataldi M, di Geronimo O, Trio R, Scotti A, Memoli A, Capone D, Guida B. Utilization of antihypertensive drugs in obesity-related hypertension: a retrospective observational study in a cohort of patients from Southern Italy. BMC Pharmacol Toxicol. 2016; 17:9. doi: 10.1186/s40360-016-0055-z.

9. Jordan J. Pathophysiology of hypertension: what are our current concepts? Internist 2015; 56:219223. doi: 10.1007/s00108-014-3572-0.

10. Kario K, Thijs L, Staessen JA. Blood Pressure Measurement and Treatment Decisions. Circ Res. 2019 Mar 29;124(7):990-1008. doi: 10.1161/CIRCRESAHA.118.313219.
11. Kobayashi K, Sato K, Hatori N, Miyakawa M. A questionnaire survey of general practitioners in Japan's Kanagawa Prefecture for the Japanese Society of Hypertension Guidelines for the Management of Hypertension 2014. ClinExpHypertens. 2017;39(8):705-710. doi: 10.1080/10641963.2017.1313852.

12. Tocci G. Cicero AF, Salvetti M, Musumeci MB, Ferrucci A, Borghi C, Volpe M. Attitudes and preferences for the clinical management of hypertension and hypertension-related cerebrovascular disease in the general practice: results of the Italian hypertension and brain survey. Clin Hypertens. 2017;23:10. doi: 10.1186/s40885017-0066-0.

13. Wermelt JA, Schunkert H. Management der arteriellen Hypertonie [Management of arterial hypertension]. Herz, 2017; 42(5), 515-526. doi:10.1007/s00059-017-4574-1.

14. Di Daniele N. Therapeutic approaches of uncomplicated arterial hypertension in patients with COPD. Pulm Pharmacol Ther. 2015; 35:1-7. doi:10.1016/j.pupt.2015.09.004.

15. Mishina IE, Sarana A., Mikhailovskaya TV, Ivanova G. E. Principles of appointment of aerobic physical training during outpatient cardiac rehabilitation / Bulletin of rehabilitation medicine. 2020. No. 3 (97). pp. 83-95. doi: 10.38025/20781962-2020-97-3-83-95. (In Russ.).

16. Miroshnikov AB, Smolensky AV, Formenov AD. New possibilities of physical rehabilitation of athletes of power sports with essential hypertension: a randomized controlled study. Bulletin of rehabilitation Medicine. 2020. No. 3 (97). pp. 76-82. doi: 10.38025/2078-1962-2020-973-76-82. (In Russ.).

17. Kulchitskaya DB, Kolbasova SN. Non-drug methods of treatment of patients with arterial hypertension / Bulletin of rehabilitation med. 2020. No. 3 (97). pp. 65-68 doi: 10.38025/2078-1962-202097-3-65-68. (In Russ).

18. Oganov RG, Shalnova SA, Maslennikova GYa. Epidemiology and prevention of cardiovascular diseases. Cardiology: national guidebook / edited by E. V. Shlyakhto. - 2nd edition, revised and enlarged - M.: GEOTAR-Media, 2019, pp. 173 195. (In Russ.).

19. Boytsov SA, Balanova YuA, Shalnova SA, Deyev AD, Artamonova GV, Gatagonova TM, Duplyakov DV, Efanov AYu. Arterial hypertension among individuals of 25-64 years of age: prevalence, awareness, treatment and control. Adapted from the materials of ESSE. Cardiovascular therapy and prevention. 2014;4;414. doi:10.15829/1728-8800-2014-4-4-14. (In Russ.).

20. Muromtseva GA, Kontsevaya A.V, Konstantinov, Artamonova GV Gatagonova TM, Duplyakov D V, 
Efanov A.Yu. The prevalence of non-infectious diseases risk factors in the Russian population in 2012-2013. the results of ESSE-RF. Cardiovascular therapy and prevention. 2014;13 (6): 4-11. doi: 10.15829/1728-8800-2014-6-4-11. (In Russ.)

21. Papathanasiou J, Troev T, Ferreira AS, Tsekoura D, Elkova H, Kyriopoulos E, Ilieva E. Advanced Role and Field of Competence of the Physical and Rehabilitation Medicine Specialist in Contemporary Cardiac Rehabilitation. Hellenic J Cardiol. 2016;57(1):16-22. doi:10.1016/s11099666(16)30013-6.

22. Troev T, Papathanasiou J. Essentials of Physical and Rehabilitation Medicine for Undergraduate Medical Students. 1st edn. Lax Book. 2016; ISBN 978-619-189-041-5.

23. Papathanasiou JV, Ilieva EM, Nikolov FP. Exercise training modes in rehabilitation of patients with chronic heart failure. Folia Med (Plovdiv). 2012;54(4):22-28. doi:10.2478/v101 53-012 -00028.

24. Achilov AA. Method of prevention, treatment and regression of hypertension, atherosclerosis, coronary heart disease, circulatory failure. Patent for the invention EN 2245700 C2, 10.02.2005. Application No. 2002123235/14 of 29.08.2002.

25. Achilov AA. Method for unloading the heart, increasing blood flow, restoring and preserving the reserve and general exchange surface of capillaries in various areas of the body at the level of regional hemodynamics. Eurasian patent No. 004621 of 24.06.2004.

26. Chazova IE, Zhernakova YuV. Clinical guidelines. Diagnosis and treatment of arterial hypertension. [Guidelines]. Systemic Hypertension. 2019; 16 (1): 6-31. doi: 10.26442/2075082X.2019.1.190179. (In Russ.).

27. Kobalava ZhD, Konradi AO, Nedogoda SV. Arterial hypertension in adults. Clinical guidelines 2020. Russian journal of cardiology. 2020; 25(3):149-218. doi: 10.15829/1560-4071-2020-33786 (In Russ.).

28. Naci H, Salcher-Konrad M, Dias S, Blum MR, Sahoo SA, Nunan D, Ioannidis JPA. How does exercise treatment compare with antihypertensive medications? A network meta-analysis of 391 randomised controlled trials assessing exercise and medication effects on systolic blood pressure. $\mathrm{Br} \mathrm{J}$ Sports Med. 2019 Jul;53(14):859-869. doi: 10.1136/bjsports-2018-099921. Epub 2018 Dec 18.

29. Saco-Ledo G, Valenzuela PL, Ruiz-Hurtado G, Ruilope LM, Lucia A. Exercise Reduces
Ambulatory Blood Pressure in Patients With Hypertension: A Systematic Review and MetaAnalysis of Randomized Controlled Trials. Journal of the American Heart Association. 2020; 9(24), e018487. doi:10.1161/JAHA.120.018487.

30. Boutcher YN, Boutcher SH. Exercise intensity and hypertension: what's new? Journal of human hypertension. 2017; 31(3), 157-164. doi:10.1038/ jhh.2016.62.

31. Ribeiro F. Resistance exercise for the management of arterial hypertension: An intervention that works!. Journal of clinical hypertension (Greenwich, Conn.), 2021; 23(5), 987-989. doi:10.1111/jch.14197.

32. Polegato BF, Paiva SAR. Hypertension and Exercise: A Search for Mechanisms. Arq Bras Cardiol. 2018;111(2):180-181. doi:10.5935/abc .20180146.

33. Maccarone MC, Magro G, Solimene U, Scanu A, Masiero S. From in vitro research to real life studies: an extensive narrative review of the effects of balneotherapy on human immune response. Sport Sci Health. 2021 May 20:1-19. doi: 10.1007/s11332-021-00778-z. Epub ahead of print..

34. Masiero S, Maccarone MC, Magro G. Balneotherapy and human immune function in the era of COVID-19. Int J Biometeorol. 2020; 64, 14331434. doi:10.1007/s00484-020-01914-z.

35. Masiero S, Maccarone MC. Health resort therapy interventions in the COVID-19 pandemic era: what next?. Int J Biometeorol. 2021. doi:10.1007/s00484-021-02134-9.

36. Gálvez I, Torres-Piles S, Ortega-Rincón E Balneotherapy, immune system, and stress response: a hormetic strategy? Int J Mol Sci. 2018; 19(6):1687. doi:10.3390/ijms19061687.

37. Bhasin MK, Denninger JW, Huffman JC, Joseph MG, Niles H, Chad-Friedman E, Goldman R, Buczynski-Kelley B, Mahoney BA, Fricchione GL, Dusek JA, Benson H, Zusman RM, Libermann TA. Specific Transcriptome Changes Associated with Blood Pressure Reduction in Hypertensive Patients After Relaxation Response Training. J Altern Complement Med. 2018 May;24(5):486-504. doi: 10.1089/acm.2017.0053. Epub 2018 Apr 4.

38. Ramos RA, Guimarães FS, Dionyssiotis Y, Tsekoura D, Papathanasiou J, Ferreira AS. Development of a multivariate model of the sixminute walked distance to predict functional exercise capacity in hypertension. J Bodyw Mov Ther. 2019;23(1):32-38. doi:10.1016/j.jbmt.2018 .01 .010 .

Submission: November 02, 2021

Revision submitted: November 22, 2021 Accepted for publication: November 22, 2021 